\title{
EDITORIAL
}

\section{DEBATE ON PEDIATRIC RESEARCH}

In the 18th century, children were viewed as property of adults. Children were also considered as cheap (not-valued) for rsearch. Early experiments on infectious diseases, new vaccines and medical procedures were often performed on children of servants, orphanages, mentally ill or physically disabled children.

In the late 19 century, objections to the use of children in research were presented by the USA AntiVivisection Society (1896). Prussian Minister for Religious, Educational and Medical Affairs issued a directive in 1900 that medical interventions other than for diagnosis, healing and immunisations children were excluded. For many years after Nuremberg, it was felt that research with children was unethical, if not illegal.

Helsinki Declaration (1964 - 2008) says children can participate in research by parental informed consent. Research involving children is only justified if it the medical interests of that child and are necessary to improve the health and well being of children. This is the most important stages of the evolution of necessity on pediatric research.

In 1974, The Pediatric Research Act established the National Commission for the Protection of Subjects of Biomedical and Behavioural Research for broad justification of research involving children under protection. Convention of Human Rights and Biomedicine Council of Europe, Oviedo 1997 express research with children can be undertaken if research questions that cannot be answered by similar research carried out in adults. G. Koren in 2003 said children are not small adults in the way their bodies function and develop. Hence, unless a new device or pharmaceutical preparation is tested in them, one cannot assume their safe and effective use in the pediatric age group. In the Europe and US, a number of legislative actions has been taken to encourage pediatric research. Pediatric research is needed bcause some diseases are typical of children and there is metabolic differences between children and adults.

\section{Shamima Parvin Lasker}

(Professor \& Head of Anatomy, City Dental College, Dhaka)

Associate Editorial

Bangladesh Journal of Bioethics 